\title{
Clinical and Genetic Varieties of Gaucher Disease in Iraqi Children
}

\author{
Mohammad Fadhil Ibraheem ${ }^{1}$ Shaymaa Jamal Ahmed ${ }^{2}$ \\ ${ }^{1}$ Department of Pediatrics, College of Medicine, University of \\ Baghdad, Baghdad, Iraq \\ ${ }^{2}$ Department of Anatomy, College of Medicine, University of \\ Baghdad, Iraq \\ Address for correspondence Mohammad Fadhil Ibraheem, MBcHB, \\ DCH, FICM, CABP, Department of Pediatrics, College of Medicine, \\ University of Baghdad, Baghdad 10071, Iraq \\ (e-mail: mohammedfadhil@comed.uobaghdad.edu.iq). \\ J Child Sci 2020;10:e202-e206.
}

\begin{abstract}
Gaucher disease (GD), which is due to a deficiency in the lysosomal enzyme $\beta$ glucocerebrosidase, is a rare genetic disorder. It is characterized by a wide variety of clinical manifestations and severity of symptoms, making it difficult to manage. A cross-sectional hospital-based genetic study was undertaken with 32 pediatric patients. We recruited 21 males and 11 females diagnosed with GD, with a male-tofemale ratio of $1.91: 1$. The mean age of the study population was $8.79 \pm 4.37$ years with an age range from 8 months to 17 years. We included patients on clinical evaluation from 2011 to 2019. An enzyme assay test was used to measure $\beta$ glucosidase enzyme activity in leukocytes and the GBA gene study was performed by polymerase chain reaction technique. We found GD type 1 in 27 (84.37\%) participants, GD type 3 in five (15.63\%) participants, while none classified as GD type 2. The dominant mutation in GD 1 was N370S in $81.5 \%$, of which two-thirds were homozygous. The second common mutation in this type of disease (L444P) was

Keywords

- Gaucher disease

- N370S

- L444P

- R463C

- GBA genes present in nine cases (40.9\%), two of whom were homozygous (9.9\%). Meanwhile, R463C was present in six cases (27.27\%), of whom one was homozygous. In GD 3, the dominant mutation was L444P as seen in $80 \%$ of the patients followed by N370S and R463C in $20 \%$. This study shows that the most common mutant allele in this study was N370S, followed by L444P. Further large-scale studies with more advanced designs are recommended to explore the sequences of GBA genes.
\end{abstract}

\section{Introduction}

Gaucher disease (GD), though the most common lysosomal storage disease, is a rare disease, with a worldwide prevalence of 1 in 75,000 live births. ${ }^{1,2}$ It is the commonest genetic disease among Jewish populations, especially among Ashkenazi Jews. ${ }^{3}$ $\mathrm{GD}$ is inherited as an autosomal recessive disorder resulting from pathogenic mutations of the GBA gene encoding the enzyme glucocerebrosidase (acid $\beta$-glucosidase), located on chromosome 1.q21.31. This usually ends up in a gradual deposition of its substrate (glucosylceramide "GlcCer" $\beta$ ) into macrophages because of the absence or low activity of this enzyme. ${ }^{4}$

received

July 15,2020

accepted

October 5, 2020
DOI https://doi.org/

10.1055/s-0040-1720956. ISSN 2474-5871.
The commonest associated clinical features include hepatosplenomegaly, thrombocytopenia, anemia, and bone involvement. Patients may develop bone pain, pathologic fractures, and joint collapse as a result of progressive infiltration of Gaucher cells in the bone and bone marrow. Avascular necrosis of the bone occurs in about one-third of patients, eventually leading to irreversible bone destruction. Thus, the rapid detection of bone involvement by diffusion-weighted MR imaging is important as skeletal changes can be reversible at an early stage. ${ }^{5}$ There are both non-neuronopathic (type 1; OMIM 230800) and neuronopathic (types 2 and 3; OMIMs 230900 and 231000) forms of the disorder. ${ }^{6}$

Copyright $\odot 2020$ Georg Thieme Verlag License terms KG Stuttgart · New York 
Identification of specific gene mutations of GD can help in patient classification. More than 350 GBA mutations of the disease have been identified, and the GBA mutation spectrum varies according to ethnic groups. ${ }^{7,8}$ The most frequent mutation in Ashkenazi Jews is N370S (also common in Caucasian populations). The second most frequent mutation, L444P, was first described in Norbottnian GD3 and is more frequently associated with GD2 and GD3. ${ }^{9}$

The most reliable method to diagnose GD is the biochemical assay of GBA activity. However, it can be coupled with a molecular diagnosis. ${ }^{10}$ Enzyme replacement therapy and substrate reduction therapy (to a lesser extent) are two available treatments for GD1 and to some extent for GD3 (they are ineffective for GD2). ${ }^{9,11}$

\section{Methods}

1. Sample collection: We conducted a cross-sectional study on 32 pediatric patients ( 21 males and 11 females) diagnosed with GD based on enzymatic and clinical evaluation. Recruitment occurred in the metabolic unit of Children Welfare Teaching Hospital (located at Medical City complex), which is one of the three tertiary hospitals in Baghdad managing pediatric metabolic pathologies. Currently, 120 children with the disease are being managed. This means 13 to 17 new cases have been added to the GD registry in Iraq over a period of 8 years (from 2011 to 2019).

We obtained a written and informed consent from participants and parents before enrolling in the study. The Ethical Committee of Children Welfare Teaching Hospital (CWTH No. 2011-287) approved our study. The study was performed according to the guidelines of the Helsinki Declaration. $^{12}$

2. Clinical findings suggestive of storage disease: Hepatomegaly and/or splenomegaly (assessed by clinical examination and abdominal ultrasound), and/or hypersplenism were noted in GD patients. In addition, we observed intense asthenia, pallor, abdominal pain, hemorrhagic syndrome, physical and/or mental subnormality, radiological signs showing involvement with long bones.

Anemia was defined as $\mathrm{Hb}$ level $<10 \mathrm{~g} / \mathrm{dL}$ for those below 6 months of age, Hb level $<9.5 \mathrm{~g} / \mathrm{dL}$ for those 6 months to 2 years old, and $\mathrm{Hb}$ level $<10.5 \mathrm{~g} / \mathrm{dL}$ for those between 2 and 12 years old. Thrombocytopenia was defined as platelet count $<130 \times 10^{3} / \mathrm{mm}^{3}$; leucopenia was defined as a white blood cell count $<4,500 / \mathrm{mm}^{3}$. $^{13}$

3. A detailed history was taken for all participants, including demographic and clinical features.

4. The diagnosis of GD: Patients were diagnosed using enzymatic assay of $\beta$-glucosidase enzyme activity in leukocytes (by dried blood sample on specific filter papers and sent by DHL (an express mail service) to metabolic laboratory/ Hamburg University Medical Center/Department of Pediatrics/Institute of Clinical Chemistry) and/or bone marrow (in some patients), and by genotype (a GBA gene study was performed in the Genetics Research Laboratory of the College of Medicine/University of Baghdad).
We classified patients into GD1, GD2, or GD3 based on the presence of neurological signs and symptoms and the rate of disease progression. ${ }^{14}$

5. DNA extraction: We obtained $1.5 \mathrm{~mL}$ of venous blood from the participants in ethylenediaminetetraacetic acid tubes and DNA was extracted using the kit (Geneon.id, United States). Nanodrop was used to measure the concentration and purity of DNA. The concentration ranged between 1.84 and $1.98 \mathrm{mg} / \mathrm{mL}$ and the purity between 1.56 and 1.84 .

6. Polymerase chain reaction (PCR): The kit used for this process was AccuPower ProFiTaq PCR PreMix.

\section{Results}

We included 32 pediatric patients: 21 males (65.6\%) and 11 females (34.4\%), with a male-to-female ratio of $1.91: 1$. The mean age of the study population was $8.79 \pm 4.3$ years, with an age range from 8 months to 17 years. The mean age at presentation was $4.02 \pm 3.26$ years. The mean age at diagnosis was $18.7 \pm 13.6$ months.

We found that the most common type of disease was type 1 GD (84.37\%), while a few of them were of type 3 GD (15.63\%). None of the participants were classified as type 2 GD. Positive consanguinity was found in 28 (87.5\%). The most prevalent age group at the time of diagnosis was 0 to 5 years, followed by 5 to 10 years, and the least between 10 to 15 years.

We diagnosed all patients using an enzyme assay test to measure $\beta$-glucosidase enzyme activity in leukocytes, and presence of Gaucher cells in bone marrow (found in three patients) as shown in - Table 1.

- Table 2 presents the clinical findings in Gaucher patients such as distended abdomen (100\%), hepatosplenomegaly (93.7\%), bleeding manifestations (68.7\%), failure to thrive (46.8\%), skeletal manifestations (37\%), and neurological manifestations (28\%).

Table 1 Clinico-demographic manifestations of the studied sample

\begin{tabular}{|c|c|c|}
\hline \multicolumn{2}{|l|}{ Variables } & \multirow{2}{*}{$\frac{\text { Number (\%) }}{21(65.6)}$} \\
\hline - Gender & Male & \\
\hline & Female & $11(34.4)$ \\
\hline \multirow{4}{*}{$\begin{array}{l}\text { - Age at } \\
\text { presentation }\end{array}$} & $<5 y$ & $22(68.75)$ \\
\hline & 5 to $10 y$ & $8(25)$ \\
\hline & $>10$ to $15 y$ & $2(6.25)$ \\
\hline & $>15 y$ & $0(0)$ \\
\hline \multirow[t]{2}{*}{ - Consanguinity } & Positive & $28(87.5)$ \\
\hline & Negative & $4(12.5)$ \\
\hline \multirow[t]{3}{*}{ - Type of disease } & GD type 1 & $27(84.37)$ \\
\hline & GD type 2 & $0(0)$ \\
\hline & GD type 3 & $5(15.63)$ \\
\hline \multirow{2}{*}{$\begin{array}{l}\text { - Methods of } \\
\text { diagnosis }\end{array}$} & Enzyme assay & $32(100 \%)$ \\
\hline & BMA + enzyme assay & $3(9.37 \%)$ \\
\hline
\end{tabular}

Abbreviations: BMA, bone marrow aspirates; GD, Gaucher disease. 
Table 2 Clinical manifestations in Gaucher disease patients according to their clinical type at the time of diagnosis

\begin{tabular}{|c|c|c|c|c|}
\hline \multicolumn{2}{|l|}{ Symptoms and signs } & $\begin{array}{l}\text { GD type } 1(N=27) \\
n(\%)\end{array}$ & $\begin{array}{l}\text { GD type } 3(N=5) \\
n(\%)\end{array}$ & $\begin{array}{l}\text { Total }(N=32) \\
n(\%)\end{array}$ \\
\hline \multicolumn{2}{|l|}{ - Distended abdomen } & $27(100)$ & $5(100)$ & $32(100)$ \\
\hline \multicolumn{2}{|l|}{ - Hepatosplenomegaly } & $26(96.3)$ & $4(80)$ & $30(93.7)$ \\
\hline \multicolumn{2}{|l|}{ - Epistaxis/Ecchymosis } & $19(70.3)$ & $3(60)$ & $22(68.7)$ \\
\hline \multicolumn{2}{|l|}{ - Failure to thrive } & $13(48.1)$ & $2(40)$ & $15(46.8)$ \\
\hline \multirow[t]{4}{*}{ Skeletal manifestations } & - Bone pain & $3(11.1)$ & $1(20)$ & $4(12.5)$ \\
\hline & - Short stature & $3(11.1)$ & $1(20)$ & $4(12.5)$ \\
\hline & - Multiple fractures & $2(7.4)$ & $0(0)$ & $2(6.25)$ \\
\hline & - Osteonecrosis & $1(3.7)$ & $1(20)$ & $2(6.25)$ \\
\hline \multirow[t]{3}{*}{ Neurological manifestations } & - Psychomotor regression & $0(0)$ & $5(100)$ & $5(15.6)$ \\
\hline & - Spastic palsy & $0(0)$ & $3(60)$ & $3(9.3)$ \\
\hline & - Generalized seizures & $0(0)$ & $1(20)$ & $1(3.1)$ \\
\hline
\end{tabular}

Table 3 Genotype profile in Iraqi Gaucher disease patients

\begin{tabular}{|c|c|c|c|}
\hline Genotype & $\begin{array}{l}\text { GD type } 1 \\
(N=27) \\
n(\%)\end{array}$ & $\begin{array}{l}\text { GD type } 3 \\
(N=5) \\
n(\%)\end{array}$ & $\begin{array}{l}\text { Total } \\
(N=32) \\
n(\%)\end{array}$ \\
\hline - N370S/N370S & 14 (51.9) & $0(0)$ & $14(43.75)$ \\
\hline - L444P/L444P & $2(7.4)$ & $4(80)$ & $6(18.75)$ \\
\hline - N 370 S/L 444 P & $5(18.5)$ & $0(0)$ & $5(15.63)$ \\
\hline - N370S/R463C & $3(11.1)$ & $1(20)$ & $4(12.5)$ \\
\hline - L444P/R463C & $2(7.4)$ & $0(0)$ & $2(6.25)$ \\
\hline - R463C/R463C & $1(3.7)$ & $0(0)$ & $1(3.12)$ \\
\hline
\end{tabular}

Abbreviation: GD, Gaucher disease.

This genetic study revealed that the dominant mutation in GD 1 was N370S (22/27), and 14 out of these 22 were homozygous. The second most common mutation in this type of the disease was L444P and was present in nine cases (with two being homozygous). Meanwhile, R463C was present in six cases, of which one was homozygous as shown in - Table 3.

\section{Discussion}

We recorded a high incidence (32) of GD over 8 years. This was because the site is a major referral center. In addition, the program of metabolic screening in Iraq commenced in 2008.

The male-to-female ratio was $2: 1$, which was in agreement with findings from Oliveira et al. ${ }^{15}$ In contrast, there were no gender predispositions in the study by Tantawy et $\mathrm{al}^{16}$ and a female predisposition as reported by Alasmar. ${ }^{17}$ All these differences can be explained by a small sample size.

Overall, the mean age of the study population was $8.79 \pm 4.37$ years and it was in line with Erdem et al, ${ }^{18}$ but incompatible with the Gaucher Registry. ${ }^{19}$ This can be explained by the low index of suspicion in our society about rare genetic diseases.

Consanguinity between parents of participants, as firstand second-degree cousins was present in 28 (87.5\%) cases. This was in agreement with findings from Alasmar in Syria, ${ }^{17}$ and Elgawhary et al in Egypt. ${ }^{20}$
Two patients with homozygous L444P mutation (7.4\%) showed type 1 phenotype and this warrants close observation as they are at risk of developing type 3 later in life. All these findings are in line with the International Collaborative Gaucher Group.

Non-neuropathic type $1 \mathrm{GD}$ is the most prevalent form worldwide as revealed by the Gaucher Registry. ${ }^{21}$

We performed a diagnosis using the enzymatic assay of $\beta$ glucosidase enzyme activity in leukocytes. In three patients, we suspected GD based on bone marrow aspiration findings, which were confirmed by enzymatic assay.

Classically, the main clinical features of GD in our study included abdominal distension, pallor, hepatosplenomegaly, and bleeding tendency, followed by skeletal involvement in the form of chronic bone pain, short stature, multiple bone fractures, and osteonecrosis. Neurological abnormalities of type 3 GD observed in this study were psychomotor regression, spastic palsy, and generalized seizures. These findings are in line with those observed by Alasmar in Syria, ${ }^{17}$ Saleem et al in Egypt, ${ }^{22}$ Shehi et al in Albania, ${ }^{23}$ and Razek et al in Egypt. $^{24}$

In Ashkenazi Jews, four mutations are responsible for $90 \%$ of the cases: N370S, L444P, 84GG, and IVS2 + 1. Among the non-Jewish population, the disease has a lower prevalence, with the most commonly identified mutations being N370S, L444P, R463C, D409H, and IVS2 + 1. To date, more than 300 different mutations have been identified in patients with a chronic non-neuronopathic form. ${ }^{25}$

To the best of our knowledge, our study is the first to perform genetic molecular examinations of GD in Iraq. Different genotypes were detected among GD patients (27 type 1 and five type 3 patients). The dominant mutation in type 1 of GD in this study was N370S (22/27), and 14 out of these 22 were homozygous, which is in line with the current knowledge in literature. The prevalence of genotype N370S in our study, in terms of homozygosity, was similar to the Ashkenazi Jewish population. This can be explained by a common root in the past, between the Jews and the Iraqis. The second common mutation in this type was L444P which was present in nine cases. Two of them were homozygous, 
requiring careful and close monitoring during the first decade, as they may develop neurological manifestations in the future. Thus, L444P is an indicator of neuronopathic disease, while the N370S allele is considered as the neuroprotective factor. $^{26}$

R463C was present in six cases, of which one was homozygous. These findings are in line with findings in other studies. ${ }^{17,18,22,23}$ The most frequent genotype in type 3 GD children in this study was homozygous for the L444P mutation (four-fifths) and heterozygous N370S/R463C in one case. These observations are convergent with the results obtained in other centers. ${ }^{27-29}$

The genotypes encountered from various treatment centers specializing in the management of GD and other lysosomal storage disorders all over the globe have revealed many differences in the offending genes, among different races. ${ }^{30}$ Together with miscegenation, a small sample size could explain these findings.

In conclusion, GD is the most common lysosomal storage disease but probably underestimated in Iraqi children due to the low index of suspicion of medical staff. There are no specific clinical features in this disease as it could converge with many other diseases. Due to the paucity of data about GD, we performed genetic evaluation and analysis in Iraqi children.

The most common mutant allele in the study population was N370S followed by L444P. The homozygous form of L444P in type 1 requires careful and close monitoring during the first decade of life because of the possibility of developing neurological complications in the future (type 3 ).

Considering the high rate of miscegenation in the Iraqi population, we strongly recommend the initiation of an active program of carrier identification and genetic counseling in families with identified cases. We also recommend advanced and more comprehensive large-scale studies of the GBA gene sequences to produce reliable findings of GD.

\section{Limitations of the Study}

This study also had a few limitations. The problems we encountered while dealing with a rare disease were limited resources (availability of diagnostic tools), inadequate provision of suitable treatment, and low index of suspicion among medical staff. The frequent interruption of drug supply (knowing that it is very costly) and long-time intervals without treatment pushed us not to include the treatment response in the study. Furthermore, the paucity of specialized metabolic centers in the Iraqi government overburdens diseased families toward additional financial hardship, leading to difficulties in communication, registry, and follow-up of cases.

\section{Conflict of Interest \\ None declared.}

\section{Acknowledgments}

We are grateful to all participants/parents and investigators for their acceptance, cooperation, and participation in this study.

\section{References}

1 Mistry PK, Belmatoug N, vom Dahl S, Giugliani R. Understanding the natural history of Gaucher disease. Am J Hematol 2015;90 (Suppl 1):S6-S11

2 Deegan PB, Cox TM. Imiglucerase in the treatment of Gaucher disease: a history and perspective. Drug Des Devel Ther 2012;6:81-106

3 Nalysnyk L, Rotella P, Simeone JC, Hamed A, Weinreb N. Gaucher disease epidemiology and natural history: a comprehensive review of the literature. Hematology 2017;22(02):65-73

4 Essabar L, Meskini T, Lamalmi N, Ettair S, Erreimi N, Mouane N. Gaucher's disease: report of 11 cases with review of literature. Pan Afr Med J 2015;20:18

5 Weinreb NJ, Goldblatt J, Villalobos J, et al. Long-term clinical outcomes in type 1 Gaucher disease following 10 years of imiglucerase treatment. J Inherit Metab Dis 2013;36(03):543-553

6 Razek AA, Abdalla A, Fathy A, Megahed A. Apparent diffusion coefficient of the vertebral bone marrow in children with Gaucher's disease type I and III. Skeletal Radiol 2013;42(02):283-287

7 Hruska KS, LaMarca ME, Scott CR, Sidransky E. Gaucher disease: mutation and polymorphism spectrum in the glucocerebrosidase gene (GBA). Hum Mutat 2008;29(05):567-583

8 Beutler E, Gelbart T. Hematologically important mutations: Gaucher disease. Blood Cells Mol Dis 1997;23(01):2-7

9 Vanier MT, Caillaud C. Disorders of sphingolipid metabolism and neuronal ceroid-lipofuscinoses. . In: Saudubray JM, Berghe G, Walter JH, eds. Inborn Metabolic Diseases Diagnosis and Treatment. 5th ed. Berlin Heidelberg: Springer-Verlag; 2012:557-559

10 Goker-Alpan O, Hruska KS, Orvisky E, et al. Divergent phenotypes in Gaucher disease implicate the role of modifiers. J Med Genet 2005;42(06):e37

11 Vellodi A, Tylki-Szymanska A, Davies EH, et al. Management of neuronopathic Gaucher disease: revised recommendations. J Inherit Metab Dis 2009;32(05):660-664

12 Bellomo-Brandão MA, Costa-Pinto EA, De Tommaso AM, Hessel G. Clinical and biochemical features of autoimmune hepatitis in 36 pediatric patients. Arq Gastroenterol 2006;43(01):45-49

13 Zimran A, Kay A, Gelbart T, et al. Gaucher disease. Clinical, laboratory, radiologic, and genetic features of 53 patients. Medicine (Baltimore) 1992;71(06):337-353

14 Burrow TA, Barnes S, Grabowski G. Prevalence and management of Gaucher disease. Pediatric Health Med Ther 2011;2:59-73

15 Oliveira MC, Oliveira BM, Queirós E, Viana MB. Clinical and nutritional aspects of Gaucher disease: prospective study of 13 children at a single center. J Pediatr (Rio J) 2002;78(06):517-522

16 Tantawy AAG, Sherif EM, Adly AAM, Hassanine S, Awad AH. Evoked potentials and neurocognitive functions in pediatric Egyptian Gaucher patients on enzyme replacement therapy: a single center experience. J Inherit Metab Dis 2013;36(06):1025-1037

17 Alasmar D. Gaucher disease in Syrian children: common mutations identification, and clinical futures. Ann Saudi Med 2015;35 (02):127-132

18 Erdemır G, Özkan T, Özgür T, Yazici Z, Özdemır Ö. Pediatric Gaucher experience in South Marmara region of Turkey. Turk J Gastroenterol 2011;22(05):500-504

19 Charrow J, Andersson HC, Kaplan P, et al. The Gaucher registry: demographics and disease characteristics of 1698 patients with Gaucher disease. Arch Intern Med 2000;160(18):2835-2843

20 Elgawhary S, Ghaffar HA, Eid K, Wahab MA, Ragab WS, Saleh WF. Prenatal genotyping of Gaucher disease in Egypt. Egypt J Med Hum Genet 2013;14(04):361-365

21 Kaplan P, Andersson HC, Kacena KA, Yee JD. The clinical and demographic characteristics of nonneuronopathic Gaucher disease in 887 children at diagnosis. Arch Pediatr Adolesc Med 2006; 160(06):603-608

22 Saleem TH, Hassan MH, El-Abd Ahmed A, et al. Clinical and genetic assessment of pediatric patients with Gaucher's disease in Upper Egypt. Egypt J Med Hum Genet 2017;18:249-255 
23 Shehi B, Boçari G, Vyshka G, Xhepa R, Alushani D. Gaucher's disease in Albanian children: casuistics and treatment. Iran J Pediatr 2011;21(01):1-7

24 Razek AAKA, Abdalla A, Barakat T, El-Taher H, Ali K. Multiparametric MR imaging using apparent diffusion coefficient and fat fraction in quantification of bone marrow in pediatrics with Gaucher disease. Clin Imaging 2018;51:318-322

25 Krasnewich DM, Sidransky E. Gaucher disease. Goldman-Cecil medicine In: Goldman L, Schafer AI, eds. 26th ed. Philadelphia: Kennedy JF; 2020:1369-1370

26 Emre S, Gürakan F, Yüce A, Rolf A, Scott R, Ozen H. Molecular analysis of Turkish Gaucher disease patients: identification of novel mutations in glucocerebrosidase $(G B A)$ gene. Eur J Med Genet 2008;51(04):315-321
27 Elmonem MA, Mahmoud IG, Mehaney DA, et al. Lysosomal storage disorders in Egyptian children. Indian J Pediatr 2016;83 (08):805-813

28 Giraldo P, Alfonso P, Irún P, et al. Mapping the genetic and clinical characteristics of Gaucher disease in the Iberian Peninsula. Orphanet J Rare Dis 2012;7(17):17

29 Lee J-Y, Lee BH, Kim G-H, et al. Clinical and genetic characteristics of Gaucher disease according to phenotypic subgroups. Korean J Pediatr 2012;55(02):48-53

30 Schwartz IVD, Göker-Alpan Ö, Kishnani PS, et al; GOS Study group. Characteristics of 26 patients with type 3 Gaucher disease: a descriptive analysis from the Gaucher outcome survey. Mol Genet Metab Rep 2017;14:73-79 